\title{
Gate-to-Gate Life Cycle Assessment for Determining Carbon Footprint of Catalytic Converter Assembly Process
}

\author{
A. N. Mustafizul Karim, H. M. Emrul Kays, Nur Aisyah and Saravanan Tanjong Tuan
}

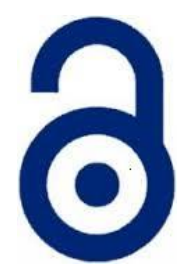

\author{
Received: 10 March 2017 \\ Accepted: 27 March 2017 \\ Published: 31 March 2017 \\ Publisher: Deer Hill Publications \\ (c) 2017 The Author(s) \\ Creative Commons: CC BY 4.0
}

\begin{abstract}
With the pursuit of embracing the circular economy, having upward trend in vehicle sales and environmental concern, sustainability has become an imperative part of the global automotive manufacturing strategies. One of the tactics to achieve this sustainable goal is to conserve and enhance the resource base by salvaging the embedded values from end-of-life product and for which, the remanufacturing can be considered as one of the most prominent epitome. Even though many of the auto parts like engine, transmissions, starters, alternators and etc. have been assessed for remanufacturability since last few decades, being a major component of a car body the catalytic converter (CC) still remains unfocused in literature. However, to examine the remanufacturability of CC, a comprehensive study for assessing its economic, social, and environmental impact is inevitable. Therefore, with an underlying aim of designing the remanufacturable CC, in this endeavour an attempt has been made to evaluate the environmental impact of its welding operations by means of energy consumption through gate-to-gate life cycle assessment. Real life data are collected from a Local Malaysian CC manufacturer. The obtained results show that the welding section has a carbon footprint of $0.203 \mathrm{kgCO}_{2} \mathrm{e} /$ unit of CC with major emission coming from the plasma arc welding. In addition to that, it is also observed that the value of carbon footprint is not only sensitive to the emission factor and processing time, but also it is responsive to the nature of the processing operations. Certainly, this observation is to motivate to change the product design from the prospect of remanufacturing.
\end{abstract}

Keywords: Carbon footprint, Life Cycle Assessment, Exhaust System, Catalytic Converter

\section{INTRODUCTION}

The unprecedented and reckless usages of the environment by raw materials extractors, manufacturers and consumers, by considering the environment as a source of unlimited resources as well as sink for the discarded endof-life products, have endangered our natural systems by Landfilling, Air and water contamination as well as industrial mishaps [1,2]. Even nowadays, these problems with landfill have become graver due to the increasing demand of land for habitation along with the waste disposal and generation of methane gas directly from landfills. For instance, in 1996 the Environment Protection Agency (EPA) reported that within less than a decade 17 states of US would reach to their landfill capacity while New York and Massachusetts even need less than 5 years as $80 \%$ of America's wastes usually go to landfills [3]. Whereas, discharge of greenhouse gases such as Carbon dioxide $\left(\mathrm{CO}_{2}\right)$, methane and CFCs into air directly by manufacturing and other human activities is rising in an exponential rate [4]. Meanwhile, the mishaps as reported in Union Carbide in India and Chernobyl in the former U.S.S.R. resulted in casualties and grave environmental impact. As a consequence, the global warming, as evident in the increases in average air and ocean temperatures, widespread melting of ice, and rising global average sea level, has become unequivocal and remains no more as a hypothetical phenomenon.

Owing to this graver catastrophe, for satisfying the needs of mankind and protect our environment, the sustainable development has become an imperative act in the manufacturing sectors [5]. One of the tactics of acquiring this goal of sustainable development is the End of Life (EOL) product recovery and for which, nowadays

A. N. M. Karim 凶, H. M. E. Kays, N. A. A. Rosland and S. T. Tuan

Department of Manufacturing and Materials Engineering

International Islamic University Malaysia

PO Box 10, 50728 Kuala Lumpur, Malaysia

E-mail: mustafizul@iium.edu.my

Reference: Karim, A. N. M., Kays, H. M. E., Rosland, N. A. A. and S. T. Tuan (2017). Gate-to-Gate Life Cycle Assessment for Determining Carbon Footprint of Catalytic Converter Assembly Process. International Journal of Engineering Materials and Manufacture, 2(1), 16-24. 
several options like reuse, recycle and remanufacture are widely adopted [6]. However, among these three strategies, the recycling process involves huge amount of energy consumption while it converts the recyclables into the raw materials. Moreover, the products manufactured through recycling process also lose some of its early added values. Even though, these kinds of deficiencies of recycling processes can possibly be minimized by adopting any of the reusing and remanufacturing processes [7]. But, reusing process does not retain the product features as like new ones, while the remanufacturing processes are envisaged to do so.

As a consequence, by featuring the positive attributes, nowadays a numbers of industries have embraced the remanufacturing epitomes within the manufacturing facilities e.g. automotive, machinery, computers, toner, cartridges, medical industry, wood industry and office furniture etc. [8, 9]. Unfortunately, a large portion of the available products manufactured from these sectors are difficult to remanufacture as most of their designs are focussed on functionality and cost irrespective to the environmental concern [10]. Thereby, many of the researchers believe that the success of this widely adopted remanufacturing practice is largely dependent on the factors like product design, efficient remanufacturing process, demand and condition of returned products $[11,12]$.

Nevertheless, among all the manufacturing sectors, the researchers have identified that the automotive sector alone can secure a share of two-thirds of remanufacturing business [13, 14]. Which is also evident in the remanufactured auto parts like engine, transmission, steering gear, starter, generator, turbo charger, alternator, compressor, steering unit and automobile door etc. [15-20]. Regrettably, the CC having the potential scope of remanufacturing, is still remaining unfocused. However, to examine the remanufacturability of CC and fill this research gap, a comprehensive study for assessing its environmental impact is inevitable. And for which, the LCA process could be one of the best possible approaches.

In literature, according to the Society of Environmental Toxicology and Chemistry (SETAC), the "Life-Cycle Assessment is a process to evaluate the environmental burdens associated with a product, process or activity by identifying and quantifying energy and materials used and wastes released into the environment; to assess the impact of those energy and material uses and releases to the environment; and to identify and evaluate opportunities to affect environmental improvements. The assessment includes the entire life-cycle of the product, process or activity, encompassing extracting and processing raw materials; manufacturing; transportation and distribution; use; re-use; maintenance; recycling, and final disposal" [21]. Even though it is generically believed that LCA should focus on the entire life cycle of a product or process, by featuring the modelling complexities and the scope of studies, the researchers have classified it as Cradle-to-grave, Cradle-to-gate, Cradle-to-cradle, Gate-to-gate and Well-to-wheel etc. Meanwhile, for any of these classes, the ISO 14040:2006, 14044:2006 and PAS 2050 are generally adopted for accounting and reporting standard of LCA.

Interestingly, with an underlying aim of assessing the environmental burden and improvements, the LCA process is widely adopted in various field of applied engineering. For instance, Smith, V. M., \& Keoleian, G. A. (2004) have applied the LCA approach for assessing the value of remanufactured engines [22]. Yang, M., \& Chen, M. (2005) quantified the environmental impact of remanufactured engine through LCA approach [23]. Warsen, J., Laumer, M., $\&$ Momberg, W. (2011) adopted LCA approach for comparing the environmental impact of newly manufactured and remanufactured manual transmission system [24]. Nevertheless, as best of our knowledge now none of the researchers has attempted to quantify the environmental impact and/or Carbon footprint of the catalytic converter. Hence in this endeavour an attempt has been made to evaluate the environmental impact by means of energy consumption through gate-to-gate life cycles assessment guideline of ISO 14040:2006 and ISO 14044:2006. However, within the scope of this gate-to-gate LCA search, a wide range of transformation and assembly operations are involved in the catalytic converter manufacturing process, the welding section is explicitly considered in this research for quantifying its environmental impact and/or Carbon footprint. Subsequent sections of this paper are arranged as follows: Section 2 presents a literature review on automotive industries in Malaysia, practice of remanufacturing epitome, application of LCA in automotive sector. Section 3 highlights the research method and collected data. The corresponding results and discussions are provided in section 5 . Finally, in Section 6 , the relevant concluding remarks are made.

\section{LITERATURE REVIEW}

Nowadays, within most of the industrialized countries, due to the depleted natural resources, diminished landfill and incineration capacities as well as the increased level of ecological pollution, the sustainable development has become an undeniable act. As a consequence, the Governments and environmental protection agencies have come up with several stricter environmental legislations and strategies to limit the industrial wastes by imposing the responsibility of waste disposal on the manufacturers. Remanufacturing, being an economical and environmental friendly business paradigm, is deemed to be helpful for the manufacturer in this regard. However, the success of this business epitome is largely dependent on the design of the product and process, and for which the quantification of carbon foot print is very much inevitable. Hence, in line with achieving this research goal, in the following subsection a brief literature review on the automotive sectors and LCA process is summarized.

\subsection{Automotive Industry in Malaysia}

The automotive sector has drawn the significant attention in manufacturing sector of Malaysia since the establishment of its two national car manufacturer named as Perusahaan Otomobil Nasional Berhad (also known as Proton) on 
May 07, 1983 and Perusahaan Otomobil Kedua Sdn. Bhd. (also known as Perodua) on August 01, 1994. Even though, at the initial stage the market share was only about 50,000 units per year, interestingly in 2013 it was reported that the Perodua and Proton had already shared $51.1 \%$ of the Total Industry Volume (TIV) [25] amounting to 655,793 units per year. This development and progression of Malaysia's automotive industry has also made the country a production centre for major automotive component manufacturers. As a consequence, today more than 690 automotive component manufacturers are reported in Malaysia producing different auto parts like body panels, brake parts, engine parts, transmission and steering parts, rubber parts and electrical and electronic parts. With this increase of share in business market, Malaysia's automotive industries have also drawn significant attention of the researchers and policy makers from the prospect of sustainability.

For instance, the government of Malaysia, in National Automotive Policy 2014 (NAP 2014) have expressed their interest and set their goal of making the automotive sector more competitive in comparison to other developed countries from the prospect of 'green'. Interestingly, the remanufacturing sector is also getting priority in Malaysia as the Malaysia Automotive Remanufacturing Roadmaps (MARR) have aimed to transform their used parts industries into the remanufacturing one.

\subsection{Remanufacturing in Automotive Industry}

In the period of 1960 to 2002, the global vehicle ownership has increased to about 573 million from 47.6 million [26]. Consequently, the transportation system is accounted for approximately $40 \%$ of the world's total oil consumption and thereby identified as one of the major sources of GHGs emission [27]. This fact makes the sustainable development crucial for the automotive manufacturers. By featuring this rising need, the Governments and environmental legislation authorities not only pushed the manufacturers to follow the green manufacturing practices but also to take back the EOL products. In this regard, remanufacturing, being an environmentally friendly and economically sound approach, is widely adopted in the global automotive sector.

For instance, nowadays in Europe many of the automotive manufacturers like Volkswagen, Audi, Bentley, Bugatti, Lamborghini, SEAT and Skoda have involved themselves in remanufacturing [28]. In China, since 2008, 14 different auto part manufacturers get involved in remanufacturing business [18]. Nevertheless, even though the remanufacturing business gets wider acceptance in the automotive sectors since last century, only a very few types of auto parts e.g. engine, transmission, gear box, alternator, steering gear, starter, generator, front/rear axles, vehicle frame, turbo chargers, compressors, water pumps, fuel delivery and brake systems are remanufactured in contemporary markets. Surprisingly, as best of our knowledge, being a major component of exhaust system, the catalytic converter has not been studied explicitly from this respect.

\subsection{Application of LCA in Automotive Sector}

The Life Cycle Assessment or Analysis (LCA) is generically defined as a method of investigation and valuation of environmental impact due to the existence of any typical product or service. In literature, two different standards, proposed by ISO under the title of ISO 14040:2006 and ISO 14044:2006, are usually adopted as guidelines of LCA. Whereas the ISO/TR 14047:2003 and ISO/TR 14047:2002 are used for the life cycle impact assessment and data documentation. Besides, nowadays the researchers have also widely adopted the PAS 2050 (Publicly Available Specifications), which is proposed by British Standards Institution (BSI) and prepared by following the guidelines of ISO14040 and ISO14044, for evaluating the product or process carbon foot print [29].

In recent times, LCA process is widely adopted for quantifying the economic, environmental and social impact of the products and processes. For instance, Smith, V. M., \& Keoleian, G. A. (2004) apply the LCA approach for assessing the value of remanufactured engines [22]. Yang, M., \& Chen, M. (2005) quantify the environmental impact of remanufactured engine through LCA approach [23]. Warsen, J., Laumer, M., \& Momberg, W. (2011) adopted LCA approach for comparing the environmental impact of newly manufactured and remanufactured manual transmission system [24]. Nevertheless, as best of our knowledge till now the environmental impact of catalytic converter has not explicitly studied by means of LCA approach.

\section{METHODOLOGY AND DATA COLLECTION}

In this research the ISO 14040 and ISO 14044 are considered as the guidelines for conducting the gate-to-gate LCA of the welding operations involved in the formation process of catalytic converter. In presence of various welding processes, the carbon footprint is computed by using the following Eq. (1)-(2).

$$
\begin{gathered}
E=\sum P \times t \\
C F P=E \times E F
\end{gathered}
$$

where:

$\mathrm{P}=$ Power rating of welding operation (KW)

$\mathrm{t}=$ Processing time (hour)

$E=$ Energy consumption of welding operation (KWh)

$\mathrm{EF}=$ Emission factors for electricity $\left(\mathrm{kgCO}_{2} \mathrm{e} / \mathrm{KWh}\right)$ 


\subsection{Data Collection}

In this research, the welding operations involved in the formation process of catalytic converter are considered as the functional units. To collect the relevant data, a detailed time study is conducted in the shop floor of a local catalytic converter manufacturer. Whereas, the standard welding parameters are gathered from the shop floor and verified by comparing with the standard parameter settings of welding operations as presented in the Metals Handbook [30].

On the basis of the collected data, a process map of the welding operations is presented in the Fig.1. Since the company classified the entire operations involved in the catalytic converter manufacturing process under four titles i.e. main body assembly, inlet assembly, outlet assembly and final assembly, the welding operations in Fig. 1 are also arranged accordingly. As no welding operation is involved in the main body assembly section, the section is excluded intentionally from our process map.

However, the details of each individual process and relevant processing times are presented in Table 1. In addition to that, for quantifying the carbon footprint, the electricity emission factor for Malaysia is considered in this research as $0.65592 \mathrm{~kg} \mathrm{CO} 2 \mathrm{e} / \mathrm{kWh}[31,32]$. Meanwhile, the standard operating conditions for each of the welding operations are collected, verified and presented in Table 2.

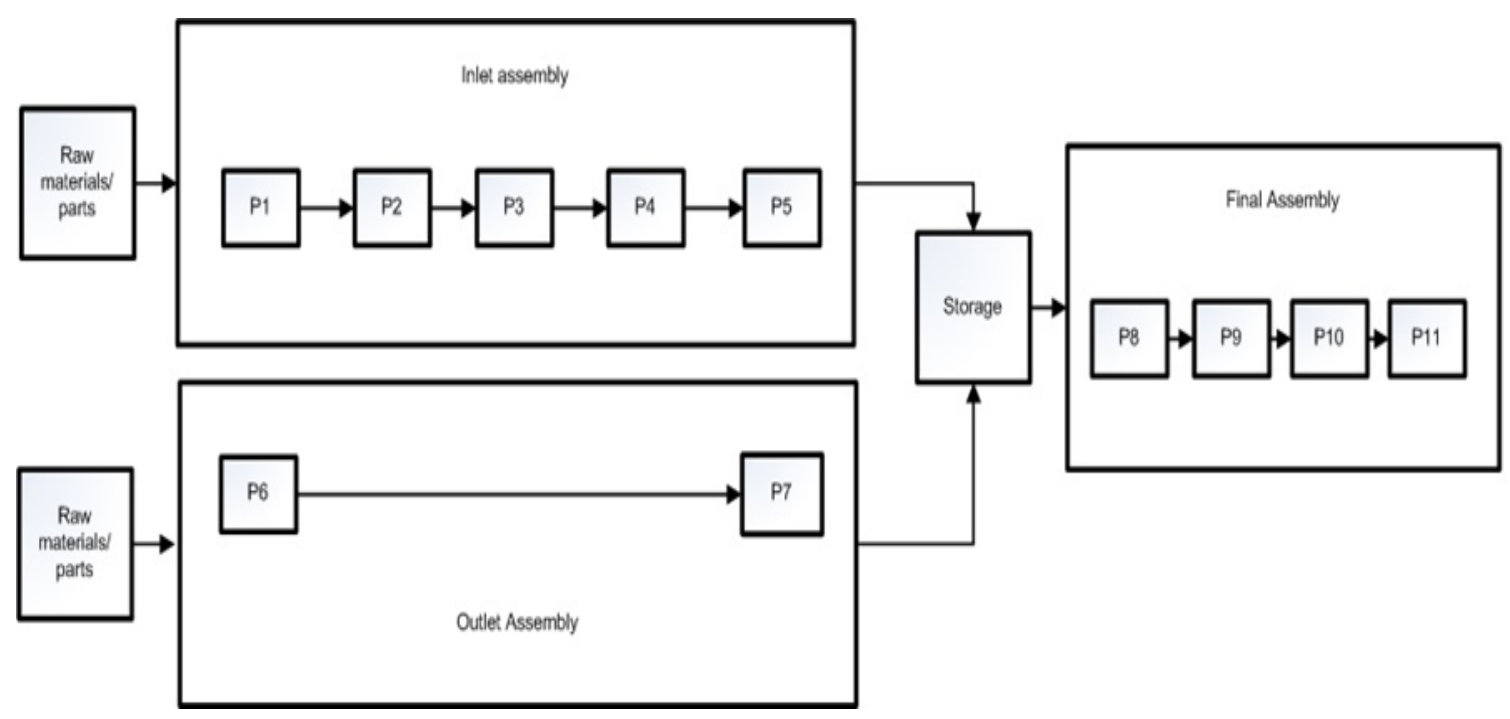

Figure 1: Process map of welding operations involved in catalytic converter manufacturing process.

Table 1: Description of welding operations and associated processing times

\begin{tabular}{|c|c|c|c|c|}
\hline Section & Process & Description & Types of Welding & $\begin{array}{l}\text { Processing } \\
\text { time, } t \text { ( } \mathrm{sec})\end{array}$ \\
\hline \multirow{5}{*}{ 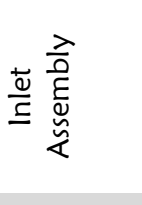 } & P1 & Assembly of Outer Cones & MIC & 41 \\
\hline & P2 & Manual TIC Welding on the Outer Cones & TIG & 32 \\
\hline & P3 & Assembly of Branches & Plasma & 89 \\
\hline & P4 & Assembly of Inlet Flange and Boss Sensor & MIC & 27 \\
\hline & P5 & Assembly Brackets & MIC & 53 \\
\hline \multirow{2}{*}{ 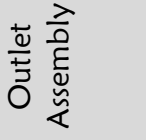 } & P6 & Assembly of Outlet Cone & MIG & 39 \\
\hline & P7 & Assembly of Outlet Flange & TIC & 25 \\
\hline \multirow{4}{*}{ 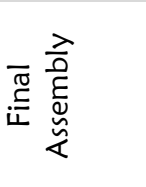 } & P8 & Assembly of Outlet Cone & MIG & 34 \\
\hline & P9 & Assembly of Inlet Branch & MIG & 52 \\
\hline & P10 & Assembly of Heat Cover Brackets & MIG & 34 \\
\hline & P11 & $\begin{array}{l}\text { Assembly of Heat Cover Branches, Heat } \\
\text { Cover Converters and Case Converter }\end{array}$ & MIC & 83 \\
\hline
\end{tabular}


Table 2: Standard operating conditions of the welding operations.

\begin{tabular}{|c|c|c|c|c|}
\hline Section & Process & Types of Welding & Voltage $(\mathrm{V})$ & Current (A) \\
\hline \multirow{5}{*}{ 㐫 $\frac{\frac{\lambda}{0}}{\underline{\Xi}}$} & P1 & MIC & 22 & 85 \\
\hline & P2 & TIG & 10 & 100 \\
\hline & P3 & Plasma arc & 30 & 115 \\
\hline & P4 & MIC & 22 & 85 \\
\hline & P5 & MIC & 22 & 85 \\
\hline \multirow{2}{*}{ 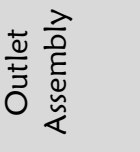 } & P6 & MIC & 22 & 90 \\
\hline & P7 & TIC & 22 & 300 \\
\hline \multirow{4}{*}{ 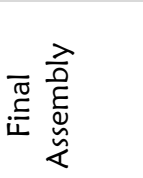 } & P8 & MIG & 22 & 90 \\
\hline & P9 & MIC & 22 & 90 \\
\hline & P10 & MIC & 22 & 90 \\
\hline & P11 & MIG & 10 & 85 \\
\hline
\end{tabular}

\section{RESULTS AND DISCUSSIONS}

For the considered real life case study of catalytic converter, the carbon footprint is computed trough the incorporation of the data presented in Table 1-2 and by using Eq. (1)-(2). The obtained results are summarized in the Table 3. It can easily be realized that the total energy consumption and carbon footprint of the considered welding processes are $0.30991 \mathrm{KWh}$ which is equivalent to $0.20327 \mathrm{kgCO}_{2} \mathrm{e}$ respectively.

\subsection{Carbon Hotspot}

Based on the obtained outputs as presented in Fig. 2, it is evident that a maximum amount of $0.05594 \mathrm{kgCO}_{2} \mathrm{e}$ of carbon footprint is traced by Process 3 while the Process 2 stands for a minimum value of $0.00583 \mathrm{kgCO}_{2} \mathrm{e}$. This finding is further supported by a statistical test result, as shown in Fig. 3, with $27 \%$ of the total emission. Thus the process of assembling the Inlet Branches emits the maximum GHGs, and it can be termed as carbon hotspot. This high emission of the process might be attributable to the specific design requirements and joining methods, power rating as well as the longest processing times. Subsequently the whole design process can be revisited for lowering the CFP impact.

\subsection{Sensitivity Analysis}

Since it is realized that the inclusion or exclusion of certain variables may have a significant impact on the entire carbon footprint value, in this subsection an endeavour has been made to analyse the sensitivity from the perspective of emission factor and processing time.

\subsubsection{Sensitivity Analysis from the Perspective of Emission Factor}

In this sensitivity analysis an attempt has made to realize the impact of changing the emission factor on the entire carbon footprint value. In this context, the electricity emission factor is changed by $\pm 10 \%$ with an increment of $\pm 5 \%$ from the original value. For these set of revised emission factors the final carbon footprint values are computed and presented in Table 4. From Table 4 it can be seen that the CFP is responsive to the emission factor. This finding also reviled the concern of energy generation mix in product manufacturing. In other words it may be possible to reduce the manufacturing carbon footprints by selecting the optimal energy generation mix.

\subsubsection{Sensitivity Analysis from the Perspective of Processing Time}

To comprehend the impact of variable processing time on the entire carbon footprint value, in this section a sensitivity analysis has been conducted from the perspective of processing times. To do so, the processing time is varied by $\pm 10 \%$ with an increment of $\pm 5 \%$ from the original value. For these set of revised processing times the final carbon footprint values are computed and presented in Table 5.

The responsiveness of the CFP values to the processing time can easily be comprehended from Table 5 . This responsiveness of the CFP values to the processing time also reviles the necessity of practicing the production planning tools and techniques (i.e. forecasting, work measurement techniques, lot sizing, balancing and scheduling etc.) for embracing the sustainable development in manufacturing shop floors. However, for better realization we extend our sensitivity analysis for two particular welding operations (i.e. P3 and P7) having maximum processing time. The output of this analysis is tabulated in Table 6.The output illustrated in Table 6, led us to a very interesting observation that impact of processing time on the CFP values depends also on the nature of operations. To clarify this observation 
the Fig. 4 is plotted. It is seen that the CFP values have not exhibited any consistent pattern while we compare it with the changes in processing time. Therefore, it can be concluded that the CFP values not only depend on the processing time but also on the process itself. And for which the change in product design to ease the remanufacturing is very much inevitable in reducing the CFP.

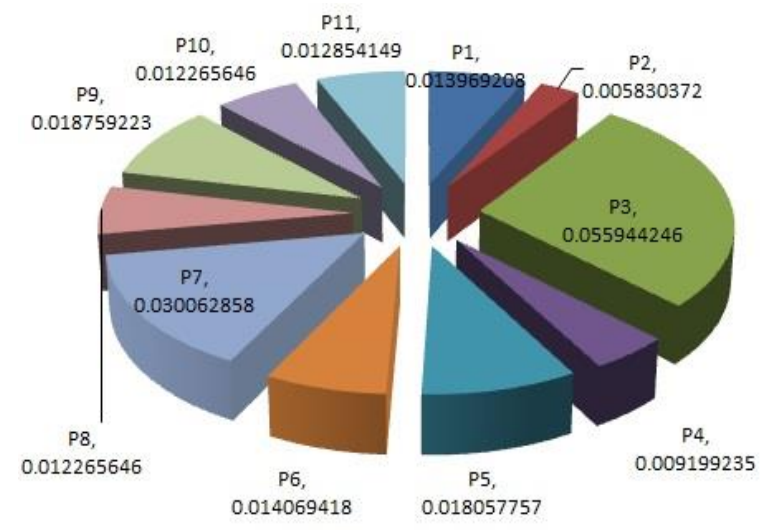

Figure 2: Breakdown of carbon footprint of welding processes.

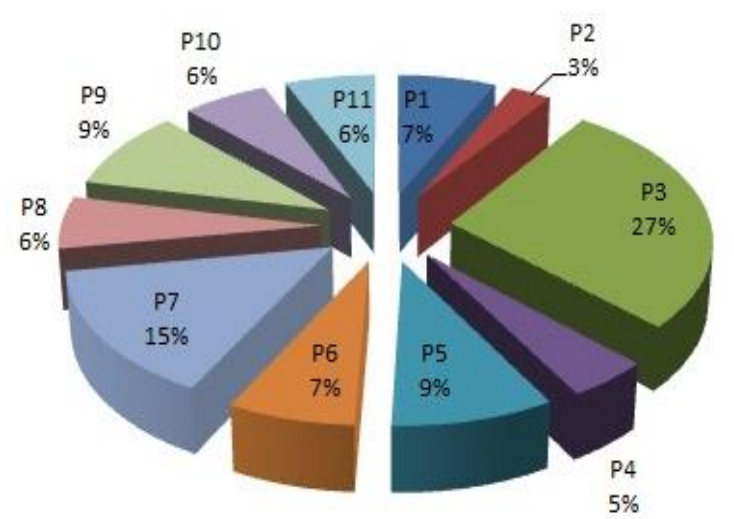

Figure 3: Breakdown of carbon footprint of welding processes according to the percentage.

Table 3: Computed carbon footprints of the welding operations.

\begin{tabular}{|c|c|c|c|}
\hline Section & Process & Consumed Energy (kWh) & Carbon footprint $\left(\mathrm{kgCO}_{2} \mathrm{e}\right)$ \\
\hline 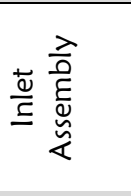 & $\begin{array}{l}\text { P1 } \\
\text { P2 } \\
\text { P3 } \\
\text { P4 } \\
\text { P5 }\end{array}$ & $\begin{array}{l}0.02129 \\
0.00888 \\
0.08529 \\
0.01402 \\
0.02753\end{array}$ & $\begin{array}{l}0.01396 \\
0.00583 \\
0.05594 \\
0.00919 \\
0.01805\end{array}$ \\
\hline 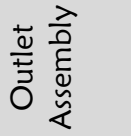 & $\begin{array}{l}\text { P6 } \\
\text { P7 }\end{array}$ & $\begin{array}{l}0.02145 \\
0.04583\end{array}$ & $\begin{array}{l}0.01406 \\
0.03006\end{array}$ \\
\hline 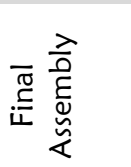 & $\begin{array}{l}\text { P8 } \\
\text { P9 } \\
\text { P10 } \\
\text { P11 }\end{array}$ & $\begin{array}{l}0.01870 \\
0.02860 \\
0.01870 \\
0.01959\end{array}$ & $\begin{array}{l}0.01226 \\
0.01875 \\
0.01226 \\
0.01285\end{array}$ \\
\hline
\end{tabular}

Table 4: Computed values for sensitivity analysis from the prospect of emission factor.

\begin{tabular}{cccc}
\hline Changes in EF (\%) & Current CFP (kgCO2e) & Revised CFP (kgCO2e) & Changes in CFP (\%) \\
\hline+10 & 0.20328 & 0.22360 & +10 \\
-10 & 0.20328 & 0.18294 & -10 \\
+5 & 0.20328 & 0.21344 & +5 \\
-5 & 0.20328 & 0.19311 & -5 \\
\hline
\end{tabular}


Table 5: Computed values for sensitivity analysis from the prospect of processing time.

\begin{tabular}{cccc}
\hline Changes in Processing time & Current CFP $\left(\mathrm{kgCO}_{2} \mathrm{e}\right)$ & Revised CFP $\left(\mathrm{kgCO}_{2} \mathrm{e}\right)$ & Changes in CFP \\
\hline$+10 \%$ & 0.20328 & 0.22361 & $+10 \%$ \\
$-10 \%$ & 0.20328 & 0.18295 & $-10.00 \%$ \\
$+5 \%$ & 0.20328 & 0.21344 & $+5 \%$ \\
$-5 \%$ & 0.20328 & 0.21344 & $-5.00 \%$ \\
\hline
\end{tabular}

Table 6: Computed values for sensitivity analysis.

\begin{tabular}{ccccc}
\hline Process & Changes in Processing time & Current CFP $\left(\mathrm{kgCO}_{2} \mathrm{e}\right)$ & Revised CFP $\left(\mathrm{kgCO}_{2} \mathrm{e}\right)$ & Changes in CFP \\
\hline P3 & $+10 \%$ & 0.20328 & 0.20887 & +2.75 \\
P3 & $-10 \%$ & 0.20328 & 0.19768 & -2.75 \\
P3 & $+5 \%$ & 0.20328 & 0.20607 & +1.38 \\
P3 & $-5 \%$ & 0.20328 & 0.20048 & -1.38 \\
P7 & $+10 \%$ & 0.20328 & 0.20478 & +1.48 \\
P7 & $-10 \%$ & 0.20328 & 0.20027 & -1.48 \\
P7 & $+5 \%$ & 0.20328 & 0.20478 & +0.74 \\
P7 & $-5 \%$ & 0.20328 & 0.20177 & -0.74 \\
\hline
\end{tabular}

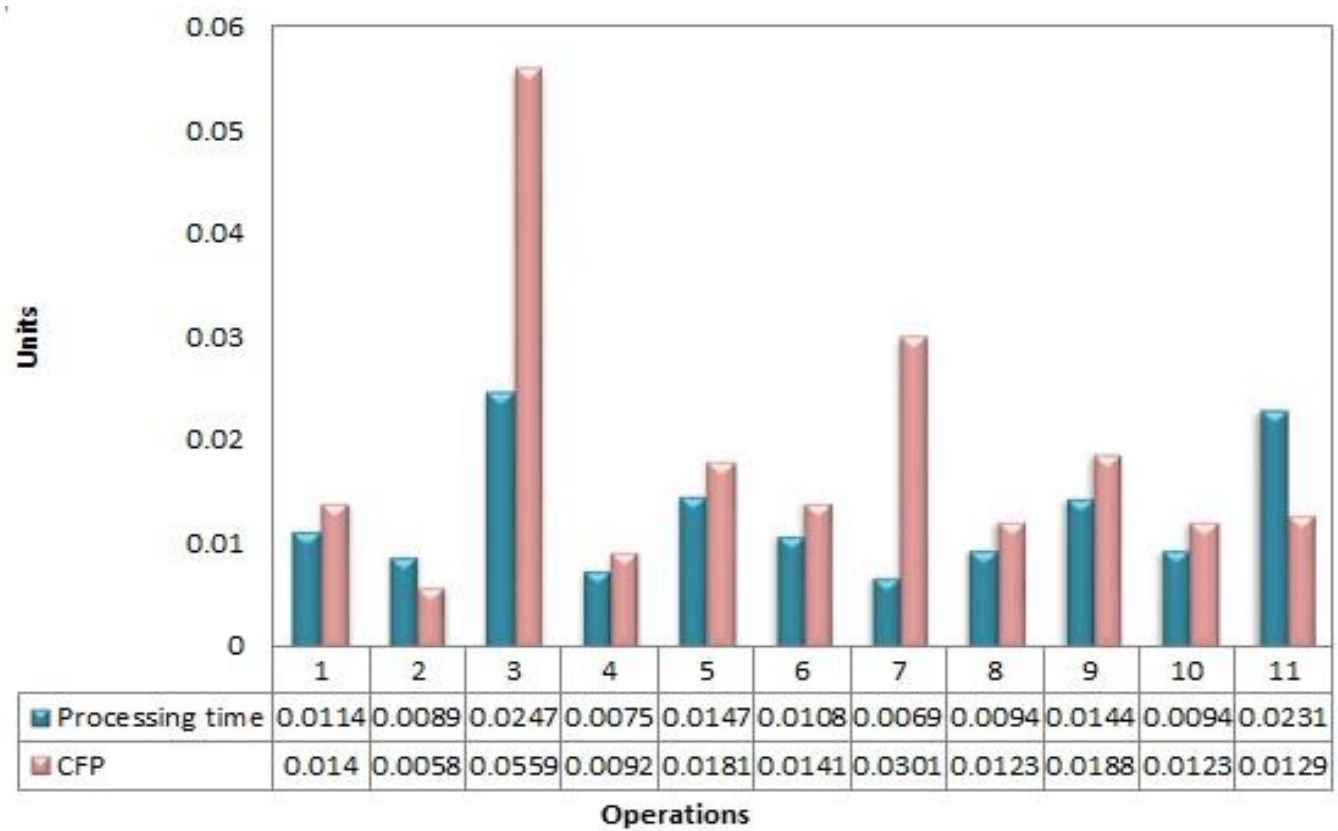

Figure 4: Changes in CFP values with respect to processing time.

\section{CONCLUSIONS}

Today, the call of millions of people as reiterated for a climate agreement is to enshrine this generation's rightful claim for a safe, sustainable, climate-resilient, green and low-carbon future. The call for climate action is not to end in Paris or in Kyoto but it should echo all the way in the whole world. As to ensure the Paris Agreement comes into fruition, participating in efforts by conducting a research in line with this global issue would be a notable contribution. With this view in consideration, this paper carries out the gate-to-gate life cycle assessment (LCA) of the welding operations of catalytic converter assembly. The computed results show that all the welding operations have a carbon footprint of $0.203 \mathrm{kgCO}_{2} \mathrm{e}$ for a unit of catalytic converter. Process 3 that assembles the inlet branches by using the plasma arc welding contributes about $27.00 \%$ of the total emission and is responsible for the majority of the emission. 
This high emission of the process might be attributable to the specific design requirements and joining methods, power rating as well as the processing times. So the whole design as well as the manufacturing process of catalytic converter can be reviewed and assessed with a goal of lowering the CFP impact. Besides, in sensitivity analysis, it is also observed that the emission factor has a direct influence over the CFP and thereby, the usage of optimal energy generation mix may help the authorities in reducing the carbon footprint by incorporating some form of renewable energy sources. Moreover, as CFP has shown responsiveness to the processing time, the production planning tools and techniques are also deemed to be helpful in optimizing the overall process CFP. It is also observed that the nature of operations has a direct influence over the CFP values. So a change in product and process design is expected to enable the organization to reduce their carbon footprint. This study is expected to be conducive to extend the analysis on the carbon footprint of entire catalytic converter by encompassing a comprehensive sensitivity analysis.

\section{ACKNOWLEDGMENT}

This study was conducted under the FRGS project (FRCS14-102-0343) funded by Ministry of Higher Education (MOHE), Malaysia. The authors are grateful to MOHE and Research Management Centre, International Islamic University Malaysia for their support.

\section{REFERENCES}

1. Abdulrahman, M. D. A., Subramanian, N., Liu, C., \& Shu, C. (2015). Viability of remanufacturing practice: a strategic decision making framework for Chinese auto-parts companies. Journal of Cleaner Production, 105, 311323.

2. Dzioubinski, O. \& Chipman, R. (1999). Trends in consumption and production: Selected minerals (No. 5). Retrieved 16th January 2017 from https://sustainabledevelopment.un.org/content/documents/347 esa 99 dp3 .pdf

3. Dixit, S. B. (2006). Product design: A conceptual development of product remanufacturing index. Retrieved 16th December 2017 from http://scholarcommons.usf.edu/etd/2504/

4. Behera, S. R., \& Dash, D. P. (2017). The effect of urbanization, energy consumption, and foreign direct investment on the carbon dioxide emission in the SSEA (South and Southeast Asian) region. Renewable and Sustainable Energy Reviews, 70, 96-106.

5. Wu, H., Lv, K., Liang, L., \& Hu, H. (2017). Measuring performance of sustainable manufacturing with recyclable wastes: A case from China's iron and steel industry. Omega, 66, 38-47.

6. King, A. M., Burgess, S. C., ljomah, W., \& McMahon, C. A. (2006). Reducing waste: repair, recondition, remanufacture or recycle?. Sustainable Development, 14(4), 257-267.

7. Thierry, M., Salomon, M., Van Nunen, J., \& Van Wassenhove, L. (1995). Strategie issues in product recovery management. California management review, 37(2), 114-135.

8. Peter Lundmark, P., Sundin, E., \& Björkman, M. (2009). Industrial challenges within the remanufacturing system. 3rd Swedish Production Symposium Göteborg, 2009. 132-138.

9. Chapman, A., Bartlett, C., McGill, I., Parker, D., \& Walsh, B. (2009). Remanufacturing in the UK. A Snapshot of the Remanufacturing Industry in the UK in 2009. Centre for Remanufacturing and Reuse, UK. http://www.remanufacturing.org.uk/pdf/story/1p342.pdf

10. Ferrer, G., (2001).Theory and methodology on the widget remanufacturing operation. European Journal of Operational Research, 135(2), 373-393.

11. Paul Goodall, P., Rosamond, E., \& Harding, J. (2014). A review of the state of the art in tools and techniques used to evaluate remanufacturing feasibility. Journal of Cleaner Production, 81, 1-15.

12. Matsumoto, M., \& Umeda, Y. (2011). An analysis of remanufacturing practices in Japan. Journal of Remanufacturing, 1(1), doi:10.1186/2210-4690-1-2.

13. Steinhilper, R. (2001). Recent trends and benefits of remanufacturing: from closed loop businesses to synergetic networks. Proceedings EcoDesign 2001: Second International Symposium on Environmentally Conscious Design and Inverse Manufacturing, 481-488.

14. Yusop, N. M., Wahab, D. A., \& Saibani, N. (2016). Realising the automotive remanufacturing roadmap in Malaysia: challenges and the way forward. Journal of Cleaner Production, 112, 1910-1919.

15. Zwolinski, P., \& Brissaud, D. (2008). Remanufacturing strategies to support product design and redesign. Journal of Engineering Design, 19(4), 321-335.

16. Zhang, T., Wang, X., Chu, J., \& Cui, P. (2010). Remanufacturing mode and its reliability for the design of automotive products. 5th International Conference on Responsive Manufacturing - Green Manufacturing (ICRM 2010), 25-31.

17. Jody, B. J., \& Daniels, E. J. (1991). Automobile shredder residue: treatment options. Hazardous waste and hazardous materials, 8(3), 219-230.

18. Zhang, T., Chu, J., Wang, X., Liu, X., \& Cui, P. (2011). Development pattern and enhancing system of automotive components remanufacturing industry in China. Resources, Conservation and Recycling, 55(6), 613-622. 
19. Jun, H. B., Lee, D. H., Kim, J. G., \& Kiritsis, D. (2012). Heuristic algorithms for minimising total recovery cost of end-of-life products under quality constraints. International Journal of Production Research, 50(19), 5330-5347.

20. Hammond, R., Amezquita, T., \& Bras, B. (1998). Issues in the automotive parts remanufacturing industry: a discussion of results from surveys performed among remanufacturers. Retrieved 16th January 2017 from https://pdfs.semanticscholar.org/eb84/8085b4858051 e8ff60b37e2c343aeb7419b0.pdf

21. Consoli, F., Allen, D., Boustead, I., Fava, J. Franklin, W., Jensen, A.A., de Oude, et al., (Eds). (1993). Guidelines for Life-Cycle Assessment: A "Code of Practice", SETAC Workshop held at Sesimbra, Portugal 31 March - 3 April. Society for Environmental Toxicology and Chemistry (SETAC).

22. Smith, V. M., \& Keoleian, G. A. (2004). The value of remanufactured engines: life-cycle environmental and economic perspectives. Journal of Industrial Ecology, 8(1-2), 193-221.

23. Yang, M., \& Chen, M. (2005). Life cycle of remanufactured engines. Journal of Central South University of Technology, 12(2), 81-85.

24. Warsen, J., Laumer, M., \& Momberg, W. (2011). Comparative life cycle assessment of remanufacturing and new manufacturing of a manual transmission. In: Hesselbach J., Herrmann C. (Eds) Clocalized Solutions for Sustainability in Manufacturing. Springer, Berlin, Heidelberg, 67-72.

25. Malaysian Automotive Association (MAA), (2013). Market Review 2013. Retrieved 25th January 2017 from http://www.maa.org.my/pdf/Market_Review_2013.pdf.

26. Dargay, J., Gately, D., \& Sommer, M. (2007). Vehicle ownership and income growth, worldwide: 1960-2030. The Energy Journal, 28 (4), 143-170.

27. Mcauley, J. W. (2003). Global sustainability and key needs in future automotive design. Environmental science \& technology, 37(23), 5414-5416.

28. Gerrard, J., \& Kandlikar, M. (2007). Is European end-of-life vehicle legislation living up to expectations? Assessing the impact of the ELV Directive on 'green'innovation and vehicle recovery. Journal of Cleaner Production, 15(1), 17-27.

29. Franchetti, M. J., \& Apul, D. (2012). Carbon footprint analysis: concepts, methods, implementation, and case studies. CRC Press.

30. Metals Handbook (1971). American Society for Metals, 6.

31. Brander. M, Sood. A, Wylie. C, Haughton. A, and Lovell. J (2011). Ecometrica: Electricity-specific emission factors for grid electricity. Retrieved 30th January, 2017 from https://ecometrica. Com / assets/Electricity-specificemission-factors-for-grid-electricity.pdf

32. Yazdani. Z., Talkhestan. G. A., Kamsah. M. Z. (2013).Assessment of Carbon Footprint at University Technology Malaysia (UTM), Applied Mechanics and Materials, 295-298,872-875. 